\title{
NOVEL WEAVING TECHNOLOGY FOR THE MANUFACTURE OF 2D NET SHAPE FABRICS FOR COST EFFECTIVE TEXTILE REINFORCED COMPOSITES
}

\author{
Duy Minh Phuong Vo, Gerald Hoffmann, Chokri Cherif \\ Institute of Textile Machinery and High Performance Material Technology (ITM), Technische Universität Dresden, \\ 01062 Dresden, Germany, Tel: +49 35146334693 \\ Corresponding author e-mail: duy.vo@tu-dresden.de
}

Abstract:

Despite significant weight and performance advantages over metal parts, today's demand for fiber-reinforced polymer composites (FRPC) has been limited mainly by their huge manufacturing cost. The combination of dry textile preforms and low-cost consolidation processes such as resin transfer molding (RTM) has been appointed as a promising approach to low-cost FRPC manufacture. This paper presents an advanced weaving technique developed with the aim to establish a more cost-effective system for the manufacture of dry textile preforms for FRPC. 2D woven fabrics with integrated net shape selvedge can be obtained using the open reed weave (ORW) technology, enabling the manufacture of $2 D$ cut patterns with firm edge, so that oversize cutting and hand trimming after molding are no longer required. The introduction of $2 D$ woven fabrics with net shape selvedge helps to reduce material waste, cycle time and preform manufacturing cost significantly. Furthermore, higher grade of automation in preform fabrication can be achieved.

\section{Keywords:}

$2 D$ net shape weaving with firm edge; ORW technology; woven fabrics for cost effective composites

\section{Introduction}

The use of fiber-reinforced polymer composites (FRPC) in structural components has been attractive to many industry sectors for decades because of their high strengthweight and stiffness-weight ratio as well as high resistance to environmental degradation, which potentially lead to bothenergy and economic benefits over metal parts [1-4]. In addition, the mechanical properties of FRPC can be optimized for a specific application by tailoring the material content as well as the orientation of reinforcing fibers in the composite. Current barrier to the widespread adoption of these materials is their very large manufacturing cost premiums, which are mainly accounted for by high material cost and low production rates $[5,6]$. In order to exploit the potential of advanced composite materials, technology advancements are required that will enable the cost-effective manufacture of FRPC at commercial volumes.

At present, utilizing dry textile reinforcement preforms in combination with low-cost consolidation processes such as resin transfer molding (RTM) or vacuum-assisted resin transfer molding (VARTM) is considered as the most effective manufacturing pathway to achieve low-cost FRPC $[3,7,8]$. Among the textile products used in preform fabrication, a large proportion is accounted for by woven fabrics. This kind of fabric has the advantage of high productivity, huge possibility of structural customization, good moldability with complicated shapes and elimination of cold storage. However, the multistage fabrication of preforms from the conventional 2D woven fabrics has been causing several disadvantages. Currently, most of the $2 \mathrm{D}$ woven fabrics made of high performance fibers are delivered in rolls with constant width. Depending on the composite end product, those fabrics are cut into patterns with particular shape that will be stacked and joined into a matched preforming tool to meet the mechanical and structural requirements. A challenging characteristic of woven fabrics is their high tendency to fray, which especially makes cut edges unstable. For this reason, oversize patterning is necessary to allow for material loss and edge deformation in the following stages. After consolidating, oversized parts have to be hand trimmed to mold tool cavity dimensions to obtain the final shape. This leads to a very inefficient use of expensive materials. Furthermore, processing fabric pieces with insufficient edge stability as well as subsequent trimming is extremely elaborated.The production rates aredecelerated andthe automation possibility is limited. As a result, the preform fabrication is very costly and consequently makes the resulting composites expensive. At present, at least $50 \%$ of FRPC total manufacturing cost is accounted for by preforms fabricating [9] Total scrap rate can be up to $30 \%$ [3]. Waste disposal and fine dust emission are other associated problems.

A promising approach to improve material efficiency as well as to optimize the processes of preform fabrication using advantageous $2 \mathrm{D}$ woven fabrics is to realize cut patterns with net shape firm cut edge. The intention of having a firm edge is to prevent the cut fabric pieces from fraying so that they can remain stable during the preforming process. Thanks to the protective firm edge, oversize patterning and subsequent trimming are no longer required. Scrap rate can be minimized. Process count, tooling and workforce can be reduced. All these factors will help to cut down preform fabricating cost significantly. Furthermore, a higher grade of automation can be achieved. 
This paper presents an advanced technique that enables a firm edge in tailored contour to be realized during weaving process. This novel technique is developed on the basis of Open Reed Weave (ORW) technology that offers a unique possibility to integrate additional multiaxial yarn systems into a conventional woven structure [10, 11]. Up to date ORW products include decorative fabrics, multiaxial fabrics, local reinforced fabrics, light-directing fabrics, woven structures with an integrated CFstrain sensor and grid-like non-crimp woven reinforcing fabrics [11-16]. Utilizing ORW technology to fabricate 2D woven fabrics with net shape firm cut edge not only shows a new perspective for a cost-effective manufacture of composite components but also opens up a new application possibility of this unique weaving technology.

\section{Structure concept and manufacturing method}

The concept of innovative 2D woven fabrics with integrated net shape firm cut edge was developed and patented by ITM [10]. In a conventional woven structure, a selected number of fine extra yarns are integrated in a way that their pathway conforms to the contour of the desired cutting pattern (Figure 1). The integrated extra yarns form a freeform selvedge. On one hand, this marks an outline, along which the fabric will be cut after weaving to achieve the desired pattern.On the other hand, this serves as a means of stabilizer that keeps the fabric edge from fraying after cutting. In this way, the resulting fabric pieces can be processed easily in preform fabrication without any yarn displacement or yarn missing. Oversize patterning and subsequent hand trimming are therefore no longer required.

ORW technology is especially suitable for the fabrication of such woven structures. Technically, an ORW machine is distinguished from a conventional loom by the reed that opens upwards and a so called special shaft that is mounted between the open reed and other conventional shafts. Thread guides in the special shaft are made into needles that are coupled with a linear motor to form a sideward movable system. During weaving, this needle system can carry out both vertical (lifting/ lowering of special shaft) and horizontal movement (shifting of linear motor). In this way, yarns that are guided by those needles can be integrated in the woven fabric in a way that one interlacing point is horizontally offset from another.[11]

The manufacturing principle of 2D woven fabrics with net shape selvedge using ORW machine is demonstrated in Figure 2. Warp yarns are passed through heddles in conventional shafts and interwoven with weft yarns to form a conventional fabric with the given pattern, for example plain weave. This is referred to as the base fabric. In the meantime, the needle systems in the special shaft are used to guide the extra yarns, which

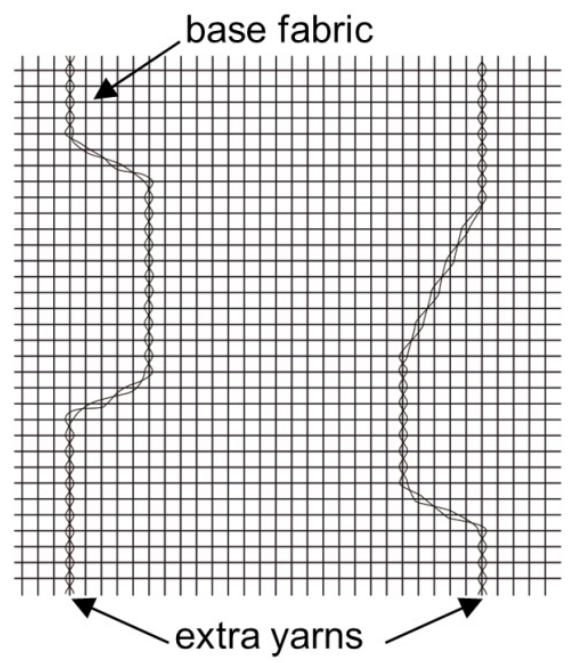

Figure 1. Concept of 2D woven fabric with integrated net shape selvedge

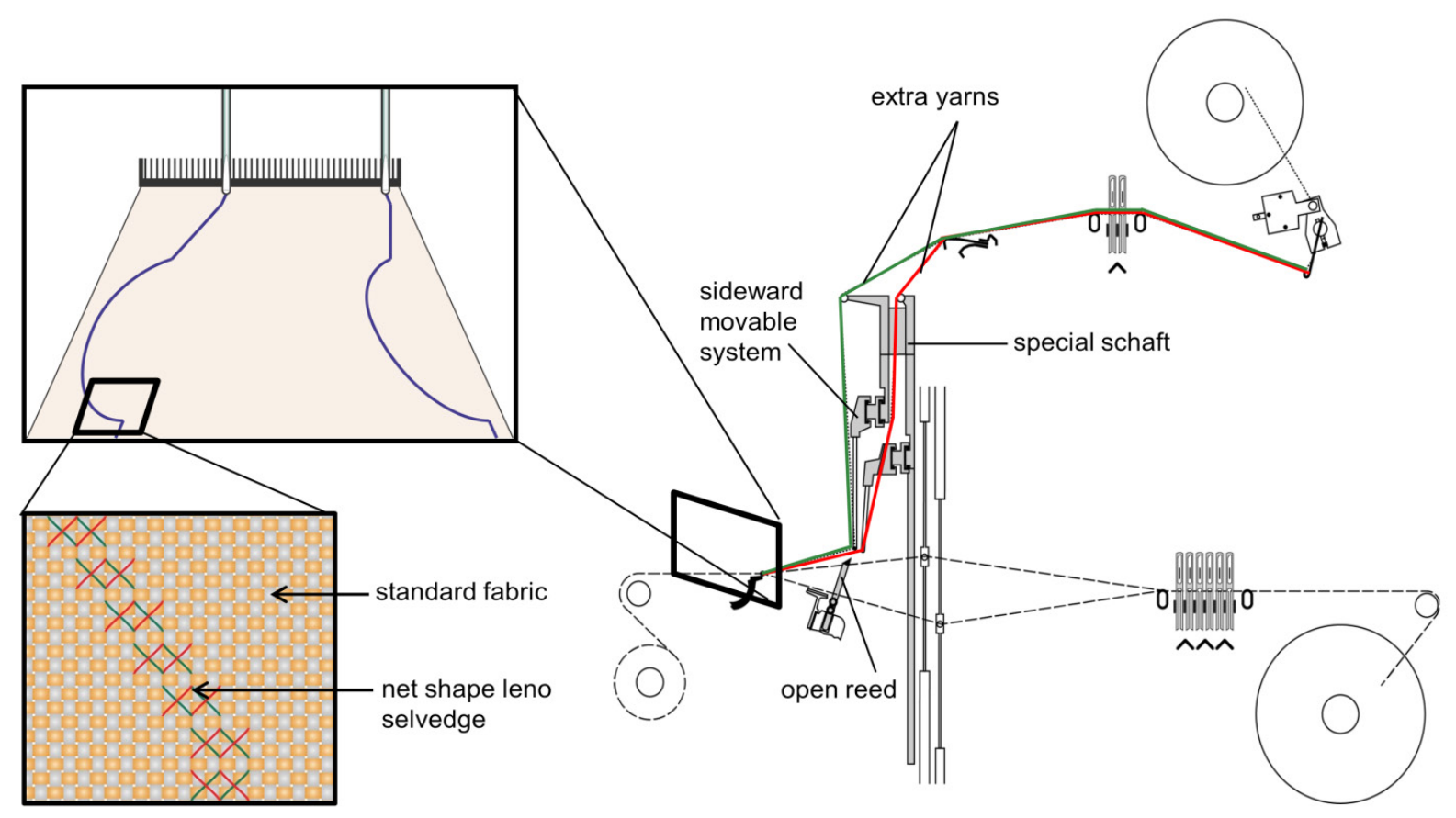

Figure 2. Manufacturing principle of $2 \mathrm{D}$ woven fabrics with net shape selvedge using ORW technology 
are delivered from a separated source. The cut edge stabilizing function of the extra yarns is obtained by means of the press-fit connection. In weaving, leno weave is known to provide very good shear stability, and therefore, is often used to create fabric selvedge as it prevents yarn slippage or yarn misplacement. By employing the warp yarns as standard thread and extra yarns as doup threads, a variety of leno configurations can be realized on an ORW machine. In composite applications, the advantage of using ORW technology to form a leno weave is that, standard threads remain stretched in the fabric structure, so that, together with other solutions to reduce yarn damage during weaving, the advanced mechanical properties of reinforcing fibers can be exploited at a higher grade in end products $[16,17]$. In addition, it is possible to optionally pair a particular doup thread with different standard threads during weaving process. By controlling the lifting plan of the special shaft in combination with appropriated sideward movements, a leno selvedge in accordance to a desired contour can be generated.

\section{Leno configuration to be applied in net shape selvedge}

As mentioned above, a large variety of leno configurations can be realized using ORW technology. In the manufacture of $2 \mathrm{D}$ woven fabric with integrated net shape selvedge for the purpose of improving material efficiency and optimizing preform fabrication process, the most essential requirements on applied leno configuration are good fraying resistance of cut edge and large flexibility in designing selvedge contour. In order to determine the appropriated configuration that meets the above requirements, various leno configurations have been explored, realized and characterized. The results are described in the following sections.
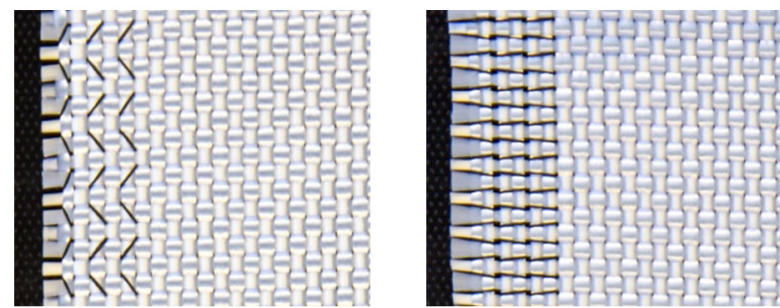

Configuration $1 \mathrm{~A}$
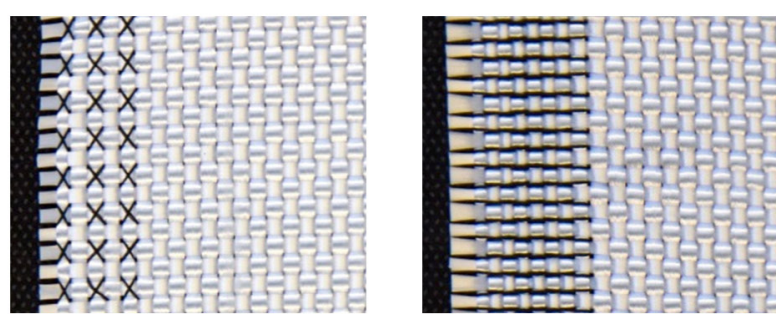

Configuration $2 \mathrm{~A}$

\subsection{Developing leno configurations}

To set a standard for the characterization and comparison, various leno configurations were first developed for straight selvedge. Technically, a variety of leno configurations can be achieved on the ORW machine by altering the following data items:

- The number of sideward movable systems

- Threading plan in each system

- Lapping movement of each system

For practical implementation, it is necessary to notice the boundary conditions limited by technical feasibility and product requirements. At ITM, the ORW rapier weaving machine PTS 4/SOD from Lindauer Dornier $\mathrm{GmbH}$, Germany was employed to fabricate $2 \mathrm{D}$ woven fabrics with net shape selvedge. On the special shaft, two sideward movable systems are available, whose movements can be controlled independently. The distance between needles in each system is $5 \mathrm{~mm}$. During weaving, each system can be shifted 5 or $10 \mathrm{~mm}$ per weft insertion and $300 \mathrm{~mm}$ in total. The base fabric was made in plain weave from the glass roving 1200 tex in both warp and weft systems. The warp density was 4 yarns $/ \mathrm{cm}$ and the weft density was 3.5 yarns $/ \mathrm{cm}$. To minimize structural as well as optical variation in resulting cut pattern, the maximum selvedge width was restricted to $20 \mathrm{~mm}$. PES textured multifilament 167 dtex was used as extra yarns due to its good processability and resin compatibility.

Figure 3 shows woven fabrics with integrated leno selvedge in different configurations that have been developed. In the first row, woven structures made with one sideward movable system (one leno system) can be observed. Maximum three extra yarns were used to meet the requirement on selvedge width. From left to right, the horizontal offset between two adjacent interlacing points of each leno yarn increases gradually from

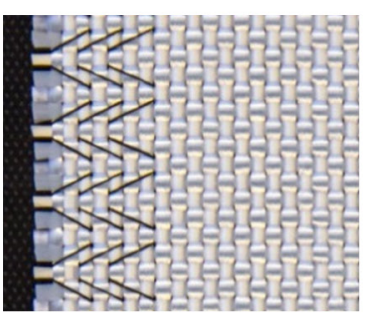

Configuration $1 \mathrm{C}$

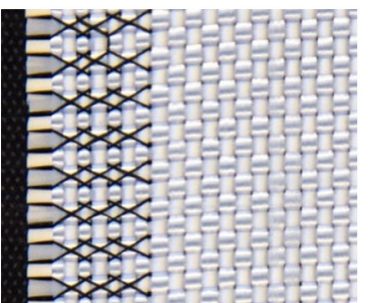

Configuration $2 \mathrm{C}$

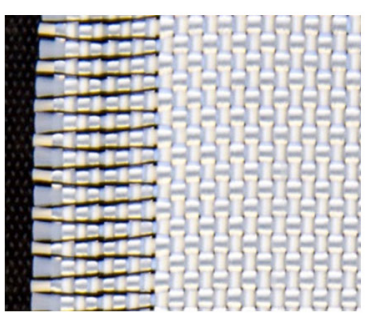

Configuration 1D

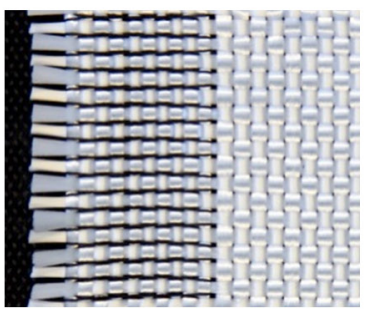

Configuration 2D

Figure 3. Woven fabrics with integrated leno selvedge in different configurations 
2.5 to $10 \mathrm{~mm}$, which are equivalent to 1 to 4 warp yarns in the base fabric. In configurations $B$ and $D$, leno yarns interlace with every single weft yarn in the base fabric, whereas in variants $A$ and $C$, interlacements take place only at every second one. Similar weave configurations were applied in woven structures in the second row, however, with two leno systems having reverse movement during weaving process.

\subsection{Evaluating fraying resistance effect on cut edge}

At the present state of the art, a standard method for determining fraying resistance of fabric cut edge is not available.At ITM, pullout strength of the most outer warp yarn in weft direction is used as are presentative index of cut edge's shear stability to evaluate the impact of integrated net shape selvedge on its fraying resistance. Pullout strength is determined using a special pull out test conducted on the universal testing machine Z2.5 from Zwick GmbH \& Co. KG. During testing, the most outer warp yarn that is fixed by extra yarnis pulled from the fabric sample in weft direction while the pulling force is measured. The higher pulling force is applied, the better fraying resistance effect is achieved. The test setup and results are shown in Figure 4. In order to verify the fraying prevention effect of integrated leno selvedges, the sample without leno selvedge was also tested and serves as reference.

Generally, fraying resistance of cut edge of 2D woven fabrics can be improved with integrated leno selvedge. Among samples having one leno system (1LS), leno selvedge in configuration $\mathrm{B}$ and $\mathrm{D}$, in which extra yarns are arranged horizontally, are significantly better fraying resistant than selvedge in configuration $A$ and $C$. This can be explained by the higher interlacing density between extra yarns and weft yarns in base fabric. Furthermore, as the horizontal offset of leno yarns in configuration $D$ is bigger than that in $B$, which consequently increases yarn friction when pulling out, cut edge of sample $1 \mathrm{LS}-\mathrm{D}$ is more stable than that of sample $1 \mathrm{LS}-\mathrm{B}$. The reverse integration of a second leno system helps to increase the fraying resistance of cut edge in most cases. One reason is that the interlacing density between extra yarns and weft yarns in base fabric has been doubled. Another important factor is the interactive binding force of extra yarns that overlap each other in the selvedge. The best improvement was obtained with configuration $B$, wherein samples $2 L S-B$ is five times more pulling resistant than samples $1 \mathrm{LS}-\mathrm{B}$. In contrast, a degradation is observed from samples 1LS-D to 2LS-D. The explanation could be that, while the interaction remains the same in both samples, extra yarns of samples $2 \mathrm{D}$ were more damaged during weaving due to high contact frequency.

\subsection{Evaluating design flexibility of leno selvedge}

As mentioned above, leno configuration to be applied in net shape selvedge should not only have good fraying resistance of cut edge but also a large flexibility to realize selvedge in various contours. Therefore, different diagonal selvedges were examined to determine the minimum slope value that can be generated with a particular leno configuration. A wider variety of contours can be generated if a more gentle diagonal selvedge is realized.

Technically, a diagonal leno selvedge is obtained by repeating a specific offset rapport in the woven structure until the required selvedge length is met. As shown in Figure 5, the slope of the resulting diagonal leno selvedge is calculated using trigonometric function:

$$
\tan \alpha=\frac{h}{b}
$$

in which $\mathrm{h}[\mathrm{cm}]$ : offset rapport length $\mathrm{b}[\mathrm{cm}]$ : offset rapport width
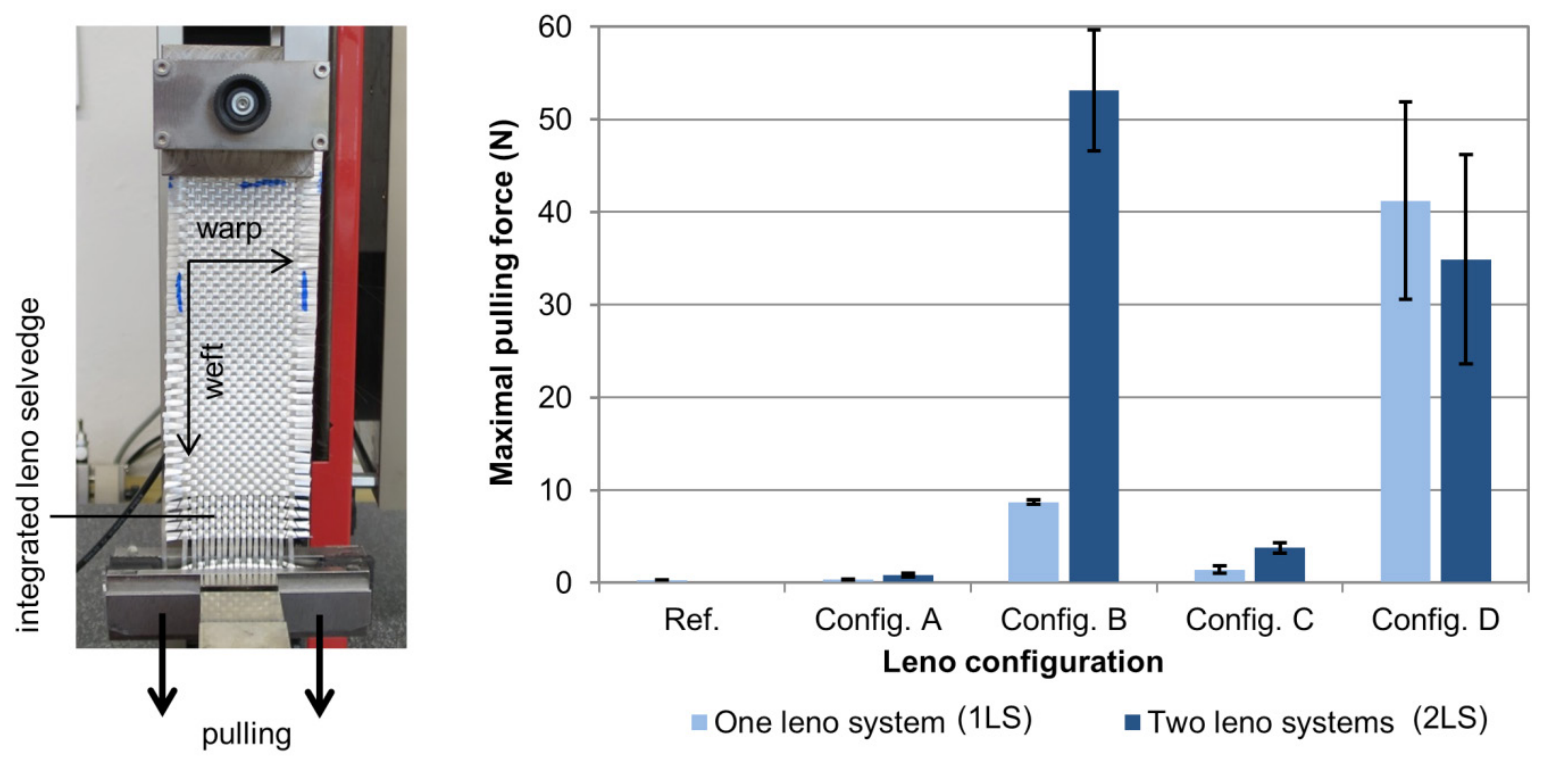

-One leno system (1LS) $\quad$-Two leno systems (2LS)

Figure 4. Setup and results of special pullout test 


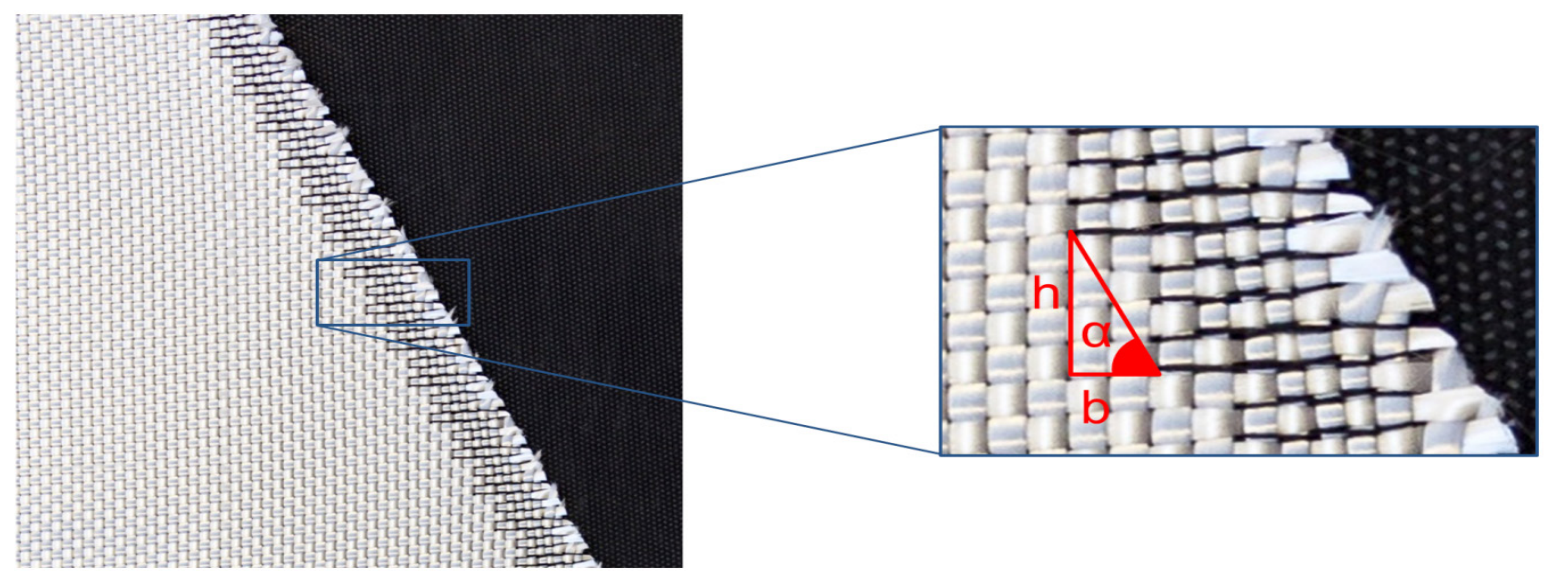

Figure 5. Calculating slope of a diagonal selvedge

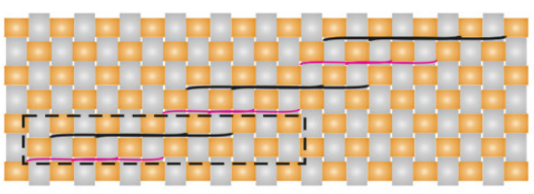

Offset rapport I - extra yarns interlace with every single weft yarn

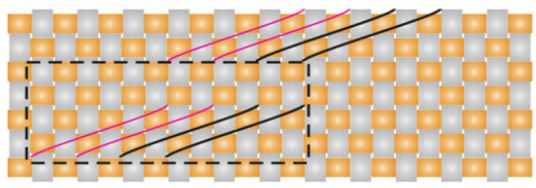

Offset rapport II - extra yarns interlace with every two weft yarns

(a)

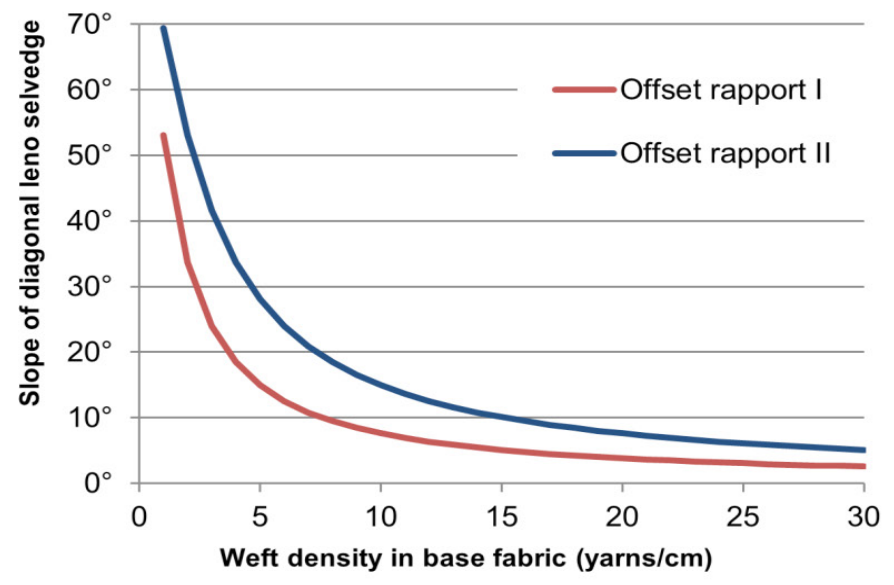

(b)

Figure 6. Minimum slope of diagonal selvedge in relation to leno configuration and weft density

It is evident that the smallest slope is obtained when offset rapport length is minimized and offset rapport width is maximized. Maximum offset rapport width, which is resulted from the horizontal offset of extra yarns, is restricted by technical feasibility of the ORW machine and remains the same for all leno configurations. Minimum offset rapport length, however, depends strongly on applied leno configuration. As can be seen in Figure 6a, offset rapport length is inversely proportional with interlacing frequency between extra yarns and weft yarns in base fabric. Hence, diagonal selvedge with the smallest slope can be generated with leno configuration in which extra yarns interlace with every single weft yarn in the base fabric. Another factor that has an impact on minimum slope value is the weft density of base fabric. A more gentle diagonal selvedge can be obtained if denser weft yarns are woven in the base fabric (Figure 6b). With the described weave parameter, diagonal leno selvedges that have a slope between $20^{\circ}$ and $90^{\circ}$ can be generated.

From the above analysis, it can be concluded that leno configuration 2LS-B, in which two leno systems are reversely integrated and extra yarns are arranged horizontally, has the best fraying prevention effect on cut edge as well as the largest flexibility to realize selvedge in various contours. Therefore, this was determined to be the most suitable leno configuration to be applied for generating net shape selvedge in a standard $2 \mathrm{D}$ woven fabric for the purpose of improving material efficiency and optimizing preform fabrication process.

\section{2D woven fabrics with net shape selvedge}

As the configuration 2LS-B has been determined as the best leno configuration for generating net shape selvedge, it was applied to fabricate 2D woven fabric with integrated selvedge in various contours. A wide range of net shape selvedges from straight line in different slope angles to freeform curve can be obtained (Figure7a, b). Desired patterns that are cut with precise dimensions along integrated leno selvedge can be draped or formed freely without the occurrence of fraying along the cut edge (Figure 7c). Structural parameters such as yarn density, fabric areal weight remain even overall in resulting structures. Thanks to the integrated leno selvedge, cut patterns can be processed easily during preforming without yarn displacement 


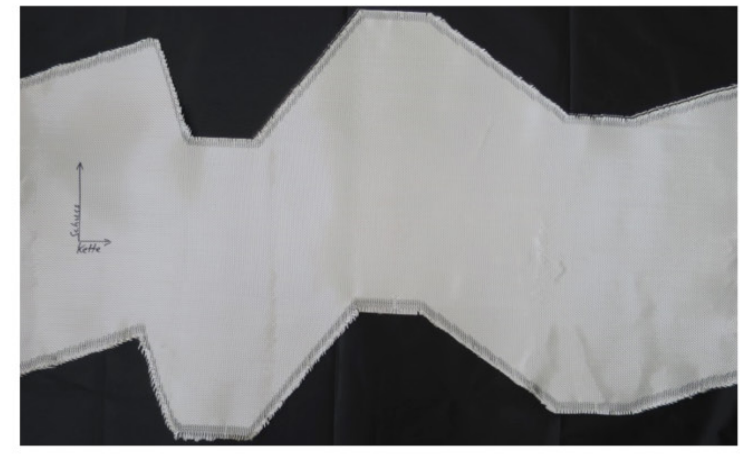

(a)

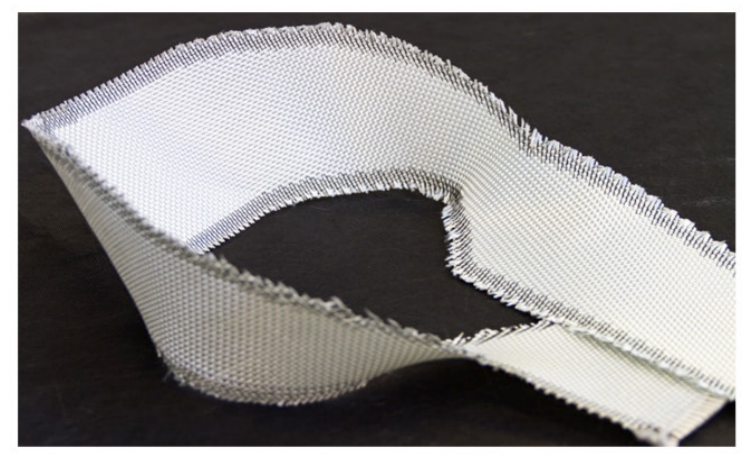

(c)

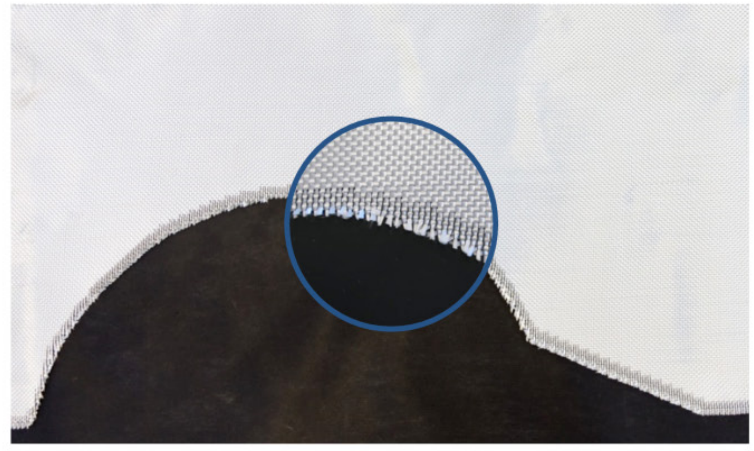

(b)

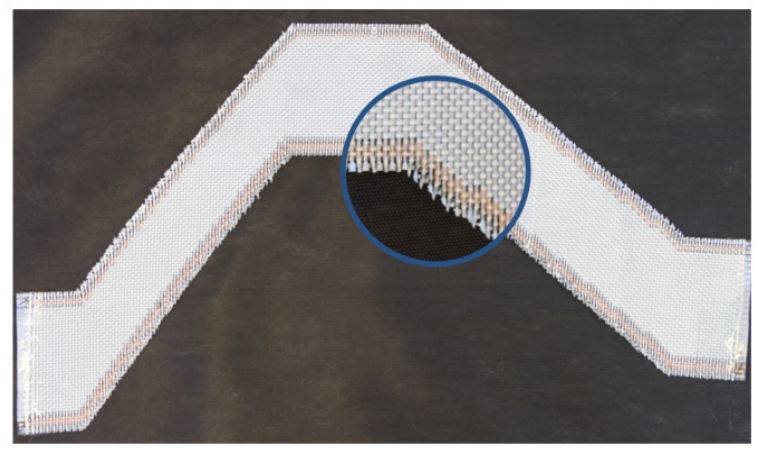

(d)

Figure 7. 2D woven fabrics fabricated with integrated net shape leno fabric

or missing. Material of base fabric can be used more efficiently as oversize cutting is no longer required. Furthermore, hand trimming after consolidation can be eliminated, which not only helps to save time, labor and tool cost but also increases automation potential in manufacturing composite components.

The advantages of net shape selvedge can be extended by using multi-material extra yarns for integrated functions. Figure $7 d$ shows a cut pattern whose selvedge is made of the described PES multifilament yarns and conductive yarns. While PES multifilament yarns remain the function of preventing fraying along cut edge, the conductive yarns can serve as signal generator for automated cutting, stacking and joining during preforming process.

\section{Conclusion}

A novel weaving technique based on the ORW technology to manufacture 2D woven fabrics with integrated net shape leno selvedge has been successfully developed. With this novel weaving technique, it is for the first time possible to obtain 2D woven fabric patterns with sufficient firm cut edge in various contours that can be applied in preforms fabrication without requiring oversized patterning and subsequent hand trimming. The manufacture of $2 \mathrm{D}$ woven fabrics with integrated net shape leno selvedge has shown a new perspective for the cost-effective manufacture of composites, wherein the manufacturing cost significantly decreases due to reduced material scrap, process count, tooling and operation cost. In addition, potential application area of unique ORW technology can be expanded.

\section{ACKNOWLEDGEMENTS}

This work presents selected results of the IGF research projects 18583BR of the Forschungsvereinigung Forschungskuratorium Textil e. V., Reinhardtstr. 12-14, 10117 Berlin and is funded through the AIF within the program for supporting the "Industrielle Gemeinschaftsforschung (IGF)" from funds of the Federal Ministry of Economics and Technology (BMWi) by a resolution of the German Bundestag.

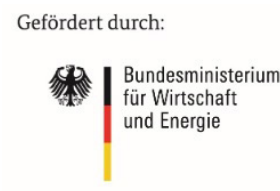

aufgrund eines Beschlusses
des Deutschen Bundestages

\section{References}

[1] Mills, A. (2001). Automation of carbon fibre preform manufacture for affordable aerospace applications. Composites Part A, 32, 955-962

[2] Bayern Innovativ Gesellschaft für Innovation und Wissenstransfer mbH. (2013). Jahresbericht 2012. Retrieved 06.27.2017. Website: http://www.bayerninnovativ.de/mediathek/publikationen/jahresbericht/ jahresbericht2012_13_profil.pdf

[3] Roland Berger Strategy Consultants. (2012). Serienproduktion von Hochfesten Faserverbundbauteilen - Perfpektiven für den Deutschen Maschinen- und Anlagenbau.Retrieved 06.27.2017. Website: http://www. afbw.eu/de/index/dienstleistungen/publikationen.html 
[4] Bannister, M. K. (2004). Development and application of advanced textile composites. Proceedings Institute of Mechanical Engineers, Volume 218, Part L, 253-260

[5] U. SDepartment ofEnergy. (2015). Quadrennial Technology Review - An assessment of energy technologies and research opportunities. Retrieved 06.27.2017. Website: https://energy.gov/downloads/qtr-2015-downloads

[6] Warren, D., Eberle, C. (2013). Barriers to Widespread Adoption of Carbon Fibers in High Volume Applications. Presented to Southern Advanced Materials in Transportation Alliance (Tennessee).

[7] Dexter, H. B. (1998). Development of Textile Reinforced Composites for Aircraft Structures. Presented at 4th International Symposium for Textile Composites (Kyoto).

[8] Campbell, F. C. (2004). Manufacturing Processes for Advanced Composites. Elsevier Advanced Technology (Oxford). 303-330

[9] Lomov, S. V. (Ed.). (2011). Non-crimp Fabric Composites - Manufacturing, properties and applications. Woodhead Publishing Limited (Cambridge)

[10] Cherif, C., Hoffmann, G., Sennewald, C. (2015). Patent EP2832906A1. TU Dresden. Pr.: DE102013108372
[11] Wahhoud, A. (2011). Neuartige Herstellung textiler Flächen durch Prozessintegration im Webvorgang. Melliand Textilberichte, 4, 195-197

[12] DORNIER. Open Reed Weave (ORW)Technology Weave and Stich in one Process. Retrieved 08.11.2017. Website: https://www.lindauerdornier.com/en/ weaving-machine/open-reed-weave-orw-technology

[13] Lenz, C., Wirmer, D., Gloy, Y.-S., Gries, T. (2014). Locally Reinforced Woven Fabrics: Mechanical and Economical Evaluation. Proceedings of the American Society for Composites 2014 - 29th Technical Conference on Composite Materials (California), Volume 2, 1135-1154

[14] ITV Denkendorf. (2016). Innovative Multiaxialgewebe für den textile Leichtbau. Technische Textilien, 1, 24-25

[15] Häntzsche, E., Schneider, B., Nocke, A., Hoffmann, G., Cherif, C. (2014). Integrally manufactured sensor systems for structural health monitoring using ORW weaving technology. Technical Textiles, 5, 175-177

[16] Weise, D., Schneider, B., Hoffmann, G., Cherif, C. (2015). ORW Technology For Non-Crimped Heavy Tow Woven Reinforcement Fabrics. Melliand International, 1, 32-33

[17] Bilek, M., Kovar, S., Skrivanek, J. (2016). Mathematical Modelling of the Heald Shaft. AUTEX Research Journal, 16(4), 175-181 